\title{
Self-rated health in Europe and its determinants: Does generation matter?
}

\author{
Isabel Aguilar-Palacio ${ }^{1,2}$ (1) $\cdot$ Ana Isabel Gil-Lacruz ${ }^{3} \cdot$ Raquel Sánchez-Recio $^{2} \cdot M^{\text {a }}$ José Rabanaque ${ }^{1,2}$
}

Received: 14 March 2017 / Revised: 10 January 2018 / Accepted: 11 January 2018

(c) Swiss School of Public Health (SSPH+) 2018

\begin{abstract}
Objectives To analyse the influence of micro- and macro-factors on self-rated health, and the role of generation on this relationship.

Methods Cross-sectional study using data from European Health Interview Surveys from 14 European countries. Individuals were divided into four generations ("silent generation", "baby boomers", and "generation X" and "Y"). We conducted multilevel analyses for each generation to study the influence of individual and national explanatory variables on self-rated health.

Results Age showed an exponential effect in older generations. Education and employment presented the strongest association with low self-rated health, especially in "baby boomers" and women (low education: OR 3.5; 95\% CI 3.2-3.9). Tobacco showed a negative effect in younger generations. Overweight and low physical activity were negatively associated with self-rated health regardless of generation. Countries from the Eastern welfare system showed the highest risk of low self-rated health and this association was higher in men for "silent generation" (OR 4.7; 95\% CI 3.0-7.6).

Conclusions The influence of individual and national factors on self-rated health varies regarding generation. The target generation and the demographic structure of a country should be taken into account to develop more accurate health policies.
\end{abstract}

Keywords Self-rated health · Generation $\cdot$ Health policy $\cdot$ Health survey $\cdot$ Welfare system

\section{Introduction}

Self-rated health is a multidimensional phenomenon that provides information about mental and physical wellness, which is associated with morbidity, mortality, and health care utilization (Wu et al. 2013). It is a good proxy for

Electronic supplementary material The online version of this article (https://doi.org/10.1007/s00038-018-1079-5) contains supplementary material, which is available to authorized users.

Isabel Aguilar-Palacio

iaguilar@unizar.es

1 Department of Preventive Medicine and Public Health, Zaragoza University, C/Domingo Miral s/n, 50009 Saragossa, Spain

2 Research Group of Health Services in Aragon (GRISSA), IIS Aragon, C/Domingo Miral s/n, 50009 Saragossa, Spain

3 Management and Organization Business Department, School of Engineering and Architecture, Zaragoza University, Gran Vía, 2, 50005 Saragossa, Spain health status in both genders regardless of the country of origin (Baćak and Ólafsdóttir 2017), and it is influenced by both individual and contextual circumstances. Among these individual circumstances that affect health perception, we know that socioeconomic factors-like employment status or educational level (Ahmad et al. 2014) - have been widely associated with self-assessed health and, in the same way, lifestyles-like the lack of physical activity or obesity-have been specifically connected to poor selfrated health (Meyer et al. 2014). As for the contextual circumstances, we know that welfare systems mediate the relationship between social determinants of health and health outcomes (Bambra 2011), as they consider each state's role in issues like housing, education, or public health services (Eikemo and Bambra 2008). In this sense, differences among regimes have been observed regarding self-rated health. For instance, people from Scandinavian and Anglo-Saxon countries report better self-rated health than people from Southern and Eastern countries (Eikemo et al. 2008). 
The contextual framework plays an important role at each stage in the personal evaluation of self-rated health. Subjects like the personal concept of health, the reference group of the individual, their health expectations, and cultural conventions modulate people's answer (Jylha 2009). In this regard, a person's generation-defined as a group of people born within the same period of time and who share specific circumstances (Bristow 2016)—could play an important role on self-rated health assessment. Generations are a natural response to political, social, and technological changes that, in general, have an international reach, and each generation's behaviour is shaped by these specific circumstances. For instance, traditionalists were defined by World War II, while it was technology what defined Generation Y (Levickaite 2010). Analysing generations in a chronological order, we observe that traditionalists value hard work, conformity, dedication, sacrifice, and patience; while baby boomers are optimistic and seek personal gratification and growth. They were the first generation to grow up in an affluent post-war society full of opportunities, which turned them into one of the most prosperous generations (Badley et al. 2015). People from Generation $\mathrm{X}$ are self-reliant, global thinkers who value balance, fun, and informality, whereas people from Generation $\mathrm{Y}$ show confidence, optimism, civic duty, sociability, street smarts, inclusivity, collaboration, and openmindedness (Gesell 2010). The literature also shows these generational differences regarding health. When changes in sociodemographic characteristics, lifestyles, and health status are considered, differences among cohorts decrease, but do not disappear (Chen et al. 2007); therefore, it is plausible to affirm that inherent generational conditions affect self-rated health.

The study of self-rated health using generational cohorts helps to control perceptions, values, and attitudes that depend on the contextual background of people's experiences (Badley et al. 2015). This makes generation a key subject to take into account when developing public health policies. To this end, this study explores the influence of individual and national factors in self-rated health, as well as how this association may change depending on generation. The purpose of this work is to identify the differences among generations, so that more accurate recommendations to improve self-rated health in European populations can be developed.

\section{Methods}

\section{Design and data set}

We performed a cross-sectional study using data from the first wave of the European Health Interview Survey
(EHIS)_conducted between 2006 and 2009, which was the last data available. The size of the final sample was 143,136 individuals from 14 European countries: Austria, Belgium, Bulgaria, Cyprus, Czech Republic, Greece, Hungary, Latvia, Malta, Poland, Romania, Slovakia, Slovenia, and Spain (Estonia and France were excluded due to the high number of missing values that they presented in some of the variables). To guarantee comparability, all the countries were provided with standard questionnaires and guidelines. More information about survey methodology can be consulted elsewhere (Eurostat 2016). Due to its sensitive information, a special request (EHIS 83/2014) was made to Eurostat to perform these analyses.

\section{Variables}

The dependent variable was self-rated health. Based on the question "How is your health in general?", we classified individuals into two categories: good self-rated health (those who answered "very good" or "good") and low self-rated health (those who responded "fair", "bad", or "very bad"). Moreover, surveyed population was grouped into four generations following the Lancaster and Stillman classification (Lancaster and Stillman 2002): Traditionalists (people born before 1946), baby boomers (those born between 1946 and 1964), Generation X (born from 1965 to 1980), and Generation Y (born from 1981).

On the other hand, individual and national variables were also included in the analyses. The variables included as individual were demographics (age, sex, and marital status), socioeconomics (educational level and employment status), and lifestyles (smoking habits, overweight, and low physical activity). For reasons of confidentiality, the age of individuals was codified by Eurostat into 5-year groups; to be able to analyse age as a continuous variable, each individual was assigned the median age of their group. Marital status was classified into "single" (never married), "married" (including registered partnership), "widowed" (not remarried), and "divorced" and not remarried (including legally separated and dissolved registered partnership). Educational level was categorised as followsaccording to the International Standard Classification of Education (ISCED): "low" (no formal education or below, or primary education), "intermediate" (lower secondary education, upper secondary, or post-secondary education, but non-tertiary education), and "high" educational level (first or second stage of tertiary education). Employment status was classified into "worker"-for pay or profit-, "unemployed", "student", "pensioner" (including both retired and permanently disabled), (unpaid) "homemaker", and "other". Regarding lifestyles, the variables included were "smoker", "overweight" and "low physical 
activity". People considered as smokers were those who smoke on a daily basis; Body Mass Index (BMI) was calculated to classify a person as overweight (BMI $>25)$; and people categorised as presenting a low physical activity were those who did not practice exercise, neither moderately (at least $150 \mathrm{~min}$ a week of moderate physical activity in the last 7 days) nor intensely (more than 75 min of intense activity during the last week), according the World Health Organization (WHO) recommendations (World Health Organization 2010). The individual variables included in the study can be observed in Table 1 .

Regarding the national variables, European countries were grouped into three categories according to Ferrera's welfare system typology (Ferrera 1996): Bismarckian (Austria and Belgium), Eastern (Bulgaria, Czech Republic, Hungary, Latvia, Poland, Romania, Slovakia and Slovenia) and Southern (Cyprus, Greece, Malta and Spain). This classification is based on both the organization and granting of social benefits. Thus, Bismarckian are those countries in which benefits are usually provided through the employer and linked to gaining power; Eastern countries' welfare system has moved from a communist universalism to a liberal regime with a limited health supply; and Southern countries have a fragmented welfare provision system with a high dependence on the family (Eikemo and Bambra 2008).

\section{Analyses}

Due to the differences between men and women in terms of self-rated health, all the analyses were stratified by sex. We also conducted a descriptive analysis of the prevalence of low self-rated health by generation. Besides, we developed multilevel analyses by each generation with a logistic function (STATA: xtmelogit), taking into account three levels of aggregation: individuals, country of residence, and welfare regime.

Reported self-rated health was the dependent variable. Our data were structured by $j$-countries, in each of which $n_{j}$ persons had been interviewed. The dependent variable (Low Self-Rated Health ${ }_{i j}$ ) summarizes whether the individual $i$ of country $j$ reports a low state of health (1: yes; 0 : otherwise). It was represented as follows:

Low Self-Rated Health ${ }_{i j}=X_{i j}^{\prime} \bar{\beta}+u_{j}+\varepsilon_{i j}$.

In our model, the $X$ set of explanatory variables includes $K$ regressors, as well as both sociodemographic variables (age, marital status, educational level, and employment

Table 1 Sample description by sex, 14 European countries, European Health Interview Survey 2006-2009

\begin{tabular}{|c|c|c|c|c|}
\hline Variables & Description of dummy variables (1: yes/0: no) & Men & Women & $\%$ Missing \\
\hline Low self-rated health $(\%)$ & $\begin{array}{l}\text { Self-rated health declared as fair, } \\
\text { bad or very bad }\end{array}$ & 30.26 & 38.59 & 4.62 \\
\hline \multicolumn{5}{|l|}{ Sociodemographic } \\
\hline Age (mean) & $\begin{array}{l}\text { Age (years) assigned at the half of } \\
\text { the period }\end{array}$ & 46.59 & 49.48 & 0.00 \\
\hline \multirow[t]{4}{*}{ Marital status (\%) } & Married & 60.00 & 53.20 & \multirow[t]{4}{*}{0.04} \\
\hline & Single & 30.83 & 22.16 & \\
\hline & Widowed & 4.56 & 17.85 & \\
\hline & Divorced/separated & 4.61 & 6.79 & \\
\hline \multirow[t]{3}{*}{ Educational level (\%) } & Low (ISCED 1) & 16.56 & 22.20 & \multirow[t]{3}{*}{0.30} \\
\hline & Intermediate (ISCED 2-4) & 65.85 & 60.32 & \\
\hline & High (ISCED 5-6) & 17.59 & 17.48 & \\
\hline \multirow[t]{6}{*}{ Employment status (\%) } & Worker & 54.86 & 40.07 & \multirow[t]{6}{*}{0.26} \\
\hline & Unemployed & 6.51 & 5.58 & \\
\hline & Student & 9.10 & 8.26 & \\
\hline & Pensioner & 28.06 & 31.45 & \\
\hline & Homemaker & 0.30 & 13.26 & \\
\hline & Other & 1.16 & 1.38 & \\
\hline \multicolumn{5}{|l|}{ Lifestyle } \\
\hline Smoker $(\%)$ & Smoker: daily smoker & 30.97 & 16.48 & 5.36 \\
\hline Overweight (\%) & Overweight: Body Mass Index $>25$ & 59.13 & 45.39 & 7.91 \\
\hline Low physical activity (\%) & $\begin{array}{l}\text { Low physical activity: no fulfillment of } \\
\text { WHO recommendations }\end{array}$ & 36.94 & 45.19 & 14.09 \\
\hline
\end{tabular}

ISCED International Standard Classification of Education, WHO World Health Organization 
status) and lifestyle variables (smoking habits, overweight, and low physical activity). The parameter $\bar{\beta}$ represents the fixed effects, which are dependent on $L$ national variables, $K-1$ individual variables and a constant. This model also sets three assumptions: the random effects $u_{j}$ are distributed normally with mean 0 and variance $\sigma_{u}^{2}=\sigma_{\beta}^{2}$, which stands for differences in the variable low self-rated health attributable to the country; the error component $\varepsilon_{i j}$ is also distributed normally with mean 0 and variance $\sigma^{2}$; and both the random effects $u_{j}$ and the error component $\varepsilon_{i j}$ are independent, being all $\varepsilon_{i j}$ independent from one another.

We repeated estimations including the welfare system of the country, where the interviewee lived. Due to parameters stability, we only present the results of the multilevel model that includes the welfare system. In addition, repeated logistic regression analyses by welfare system and country were performed. Due to the large amount of information, these results are available as supplemental material.

Finally, to verify whether generations are accurately specified in this study, independent estimations have been carried out for each generation (Cogin 2012). Results were reported using Odds Ratios (OR) and their confidence interval levels $(95 \% \mathrm{CI})$.

\section{Results}

\section{Low self-rated health}

33,701 people were traditionalists, 47,133 were baby boomers, 34,196 belonged to Generation X, and 28,106 were part of Generation Y. Figure 1 shows the prevalence of low self-rated health by generation and welfare regime, and stratified by sex. In both sexes, the Eastern regime showed the highest levels of low self-rated health. Results by country and generation are available in figures $1 \mathrm{~s}$ and $2 \mathrm{~s}$.

The prevalence of low self-rated health by generation and according to individual determinants can be observed in Table 2. Widowed, people with a low educational level and pensioners showed the highest prevalence of low selfrated health. With the exception of pensioners, who showed sustained high prevalence of low self-rated health regardless their generation, all other individual factors had a decreasing trend from traditionalists to Generation Y.

\section{Traditionalists}

Tables 3 and 4 show the results of multilevel analyses by generation. Among traditionalist men, living in an Eastern regime (OR 4.7; 95\% CI 3.0-7.6), being unemployed (OR
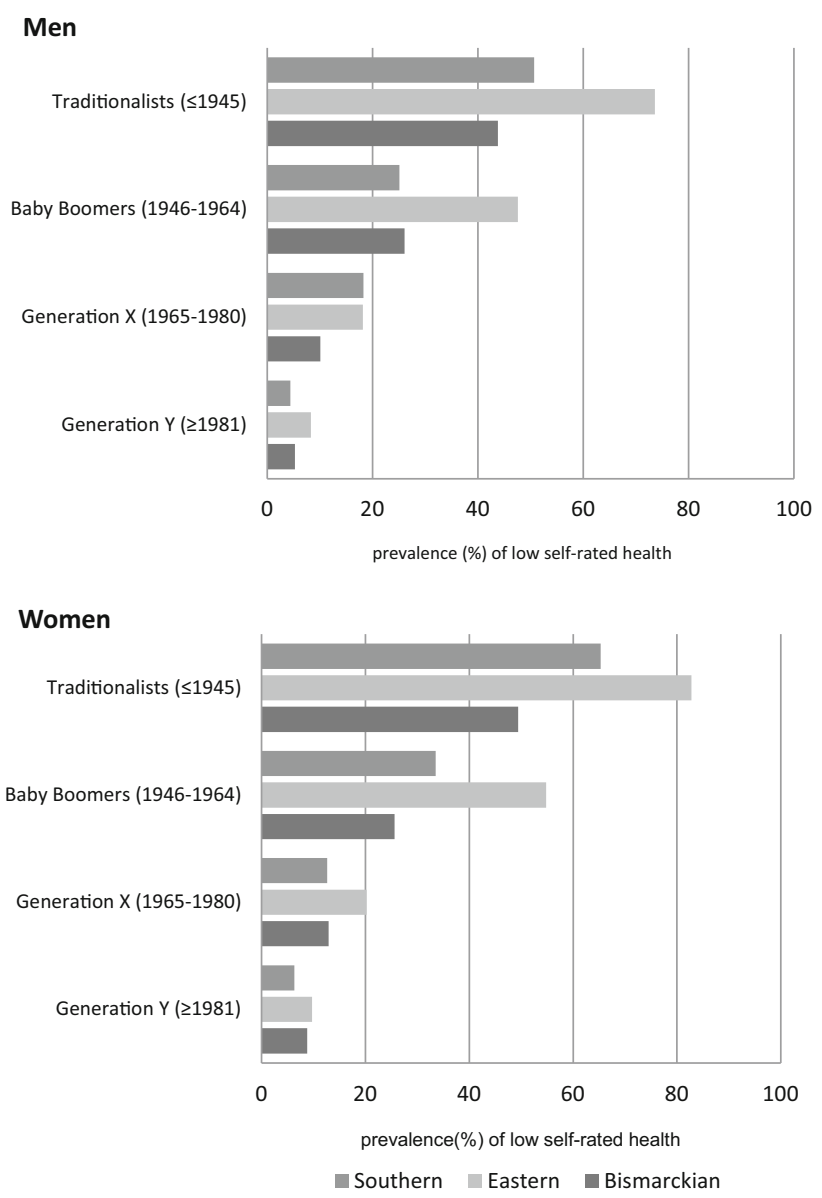

Fig. 1 Prevalence (\%) of low self-rated health by generation and welfare regime, by sex. 14 European countries, European Health Interview Survey 2006-2009

3.2; 95\% CI 1.6-6.2) and having a low educational level (OR 2.6; 95\% CI 2.3-3.0) were highly associated with low self-rated health; moreover, age showed an exponential effect $\left(\mathrm{age}^{2}\right.$ variable). This generation presents the lowest random effect in the multilevel model. In women, being a student (OR 3.0; 2.6-3.4) and belonging to an Eastern regime (OR 3.9; 95\% CI 2.5-6.0) were also strongly associated with low self-rated health levels. Regarding lifestyles, both overweight women and those stating a low physical activity were connected to low self-rated health. On the contrary, women smokers had a lower risk of low self-rated health than non-smokers (OR $0.8 ; 95 \%$ CI 0.7-1.0).

\section{Baby boomers}

In men baby boomers, being a pensioner (OR 4.2; 95\% CI 3.9-4.6) and belonging to an Eastern regime (OR 3.9; 95\% CI 2.5-6.3) were strongly associated with low self-rated health. In addition, a low educational level showed a similar effect on low self-rated health to that in 
Table 2 Prevalence (\%) of low self-rated health by generation, stratified by sex according to individual determinants, 14 European countries, European Health Interview Survey 2006-2009

\begin{tabular}{|c|c|c|c|c|c|c|c|c|}
\hline & \multicolumn{4}{|l|}{ Men } & \multicolumn{4}{|l|}{ Women } \\
\hline & $\begin{array}{l}\text { Traditionalists } \\
(\leq 1945)\end{array}$ & $\begin{array}{l}\text { Baby } \\
\text { Boomers } \\
(1946- \\
1964)\end{array}$ & $\begin{array}{l}\text { Generation } \\
\text { X (1965- } \\
1980)\end{array}$ & $\begin{array}{l}\text { Generation Y } \\
(\geq 1981)\end{array}$ & $\begin{array}{l}\text { Traditionalists } \\
(\leq 1945)\end{array}$ & $\begin{array}{l}\text { Baby } \\
\text { Boomers } \\
(1946- \\
1964)\end{array}$ & $\begin{array}{l}\text { Generation } \\
\text { X (1965- } \\
1980)\end{array}$ & $\begin{array}{l}\text { Generation Y } \\
(\geq 1981)\end{array}$ \\
\hline \multicolumn{9}{|l|}{ Sociodemographic } \\
\hline \multicolumn{9}{|l|}{ Marital status } \\
\hline Married & 60.05 & 36.71 & 13.47 & 7.44 & 67.28 & 42.75 & 15.67 & 8.95 \\
\hline Single & 53.28 & 40.82 & 14.40 & 6.78 & 60.16 & 37.99 & 17.00 & 8.45 \\
\hline Widowed & 65.51 & 47.63 & 29.82 & 20.00 & 75.17 & 57.33 & 28.70 & 22.73 \\
\hline $\begin{array}{l}\text { Divorced/ } \\
\text { separated }\end{array}$ & 54.59 & 40.52 & 19.48 & 7.41 & 65.22 & 43.26 & 22.68 & 22.92 \\
\hline \multicolumn{9}{|l|}{ Educational level } \\
\hline Low & 65.95 & 45.82 & 20.00 & 11.55 & 76.27 & 56.64 & 29.85 & 15.14 \\
\hline Intermediate & 61.26 & 40.44 & 15.63 & 6.67 & 67.88 & 45.23 & 18.22 & 8.64 \\
\hline High & 43.54 & 21.43 & 7.88 & 5.00 & 51.81 & 25.90 & 10.50 & 6.77 \\
\hline \multicolumn{9}{|l|}{ Employment } \\
\hline Worker & 36.61 & 26.76 & 11.67 & 6.38 & 50.00 & 31.40 & 14.13 & 8.54 \\
\hline Unemployed & 53.66 & 45.86 & 21.79 & 10.73 & 65.85 & 51.48 & 23.99 & 11.89 \\
\hline Student & 45.83 & 34.48 & 2.86 & 4.80 & 73.68 & 37.78 & 11.72 & 6.85 \\
\hline Pensioner & 61.70 & 64.99 & 82.42 & 75.00 & 72.82 & 66.86 & 79.11 & 74.71 \\
\hline Homemaker & 55.88 & 48.28 & 28.21 & 15.00 & 62.02 & 39.81 & 17.53 & 11.17 \\
\hline Other & 40.00 & 52.38 & 30.68 & 8.79 & 72.76 & 55.17 & 19.68 & 9.43 \\
\hline \multicolumn{9}{|l|}{ Lifestyle } \\
\hline Smoker & 58.44 & 39.38 & 16.48 & 8.53 & 59.50 & 43.57 & 21.91 & 12.74 \\
\hline Overweight & 59.25 & 37.99 & 14.62 & 7.57 & 65.69 & 50.85 & 21.92 & 12.44 \\
\hline $\begin{array}{l}\text { Low physical } \\
\text { activity }\end{array}$ & 64.73 & 41.99 & 16.93 & 10.24 & 72.71 & 44.94 & 17.66 & 9.60 \\
\hline
\end{tabular}

Low educational level: International Standard Classification of Education (ISCED) 1; intermediate educational level: ISCED 2-4; high educational level: ISCED 5-6; smoker: daily smoker; overweight: Body Mass Index > 25; low physical activity: no fulfillment of World Health Organization recommendations

traditionalists, and age was positively correlated with low self-rated health (OR 1.8; 95\% CI 1.6-2.1) resulting in an exponential effect. In women, belonging to an Eastern country and being overweight (OR $1.4 ; 95 \%$ CI 1.4-1.5) were also associated with low self-rated health.

\section{Generation X}

When men from Generation $\mathrm{X}$ were evaluated, belonging to the pensioner group showed the highest risk of low selfrated health (OR 32.0; 95\% CI 23.6-43.5). Working as a homemaker, being widowed and living in an Eastern regime were also associated with low self-rated health. In women, having a low educational level and being a pensioner showed the highest association with low self-rated health.

\section{Generation $Y$}

Finally, low self-rated health in Generation Y men was particularly associated with being a pensioner (OR 46.9; 95\% CI 29.3-75.2), having a low educational level (OR $2.1 ; 95 \%$ CI 1.5-2.9) and presenting a low physical activity (OR 1.9; 1.6-2.3). Being a student, however, showed a protective effect (OR 0.8; 95\% CI 0.6-1.0), while living in an Eastern regime was associated with a higher risk of low self-rated health (OR 2.7; 95\% CI 1.5-5.1). In women, low self-rated health was related to being divorced (OR 2.7; 95\% CI 1.7-4.2). In addition, smoking showed the highest effect in this generation (OR 1.6; 95\% CI 1.4-1.9). 
Table 3 Determinants of low self-rated health by male generations using multilevel analyses, 14 European countries, European Health Interview Survey 2006-2009

\begin{tabular}{|c|c|c|c|c|}
\hline & $\begin{array}{l}\text { Traditionalists } \\
\text { OR }(95 \% \mathrm{CI})\end{array}$ & $\begin{array}{l}\text { Baby Boomers } \\
\text { OR }(95 \% \text { CI })\end{array}$ & $\begin{array}{l}\text { Generation X } \\
\text { OR }(95 \% \mathrm{CI})\end{array}$ & $\begin{array}{l}\text { Generation Y } \\
\text { OR }(95 \% \text { CI) }\end{array}$ \\
\hline \multicolumn{5}{|l|}{ Fixed effects } \\
\hline \multicolumn{5}{|l|}{ Sociodemographic } \\
\hline Age & $1.2(1.1-1.4)^{*}$ & $1.8(1.6-2.1)^{*}$ & $0.9(0.7-1.1)$ & $1.1(1.0-1.2)^{*}$ \\
\hline $\mathrm{Age}^{2}$ & $1.0(1.0-1.0)^{*}$ & $1.0(1.0-1.0)^{*}$ & $1.0(1.0-1.0)$ & $1.0(1.0-1.0)$ \\
\hline Married & Ref & Ref & Ref & Ref \\
\hline Single & $1.0(0.8-1.2)$ & $1.2(1.1-1.4)^{*}$ & $1.0(0.9-1.1)$ & $1.1(0.9-1.4)$ \\
\hline Widowed & $0.9(0.7-1.1)$ & $1.0(0.8-1.2)$ & $2.4(1.3-4.5)^{*}$ & $2.3(0.4-11.8)$ \\
\hline Divorced & $0.9(0.7-1.1)$ & $1.1(1.0-1.3)$ & $1.2(0.9-1.4)$ & $0.6(0.2-2.0)$ \\
\hline Low education & $2.6(2.3-3.0)^{*}$ & $2.6(2.3-3.0)^{*}$ & $2.0(1.6-2.4)^{*}$ & $2.1(1.5-2.9)^{*}$ \\
\hline $\begin{array}{c}\text { Intermediate } \\
\text { education }\end{array}$ & $1.7(1.5-1.9)^{*}$ & $1.8(1.7-2.0)^{*}$ & $1.7(1.4-1.9)^{*}$ & $1.3(1.0-1.7)^{*}$ \\
\hline High education & Ref & Ref & Ref & Ref \\
\hline Worker & Ref & Ref & Ref & Ref \\
\hline Unemployed & $3.2(1.6-6.2)^{*}$ & $1.9(1.7-2.1)^{*}$ & $1.9(1.6-2.2)^{*}$ & $1.5(1.2-1.9)^{*}$ \\
\hline Student & $1.1(0.5-2.8)$ & $2.5(1.1-5.7)^{*}$ & $0.4(0.1-1.1)$ & $0.8(0.6-1.0)^{*}$ \\
\hline Pensioner & $2.2(1.8-2.6)^{*}$ & $4.2(3.9-4.6)^{*}$ & $32.0(23.6-43.5)^{*}$ & $46.9(29.3-75.2) *$ \\
\hline Homemaker & $2.4(1.4-4.1)^{*}$ & $2.3(1.3-4.1)^{*}$ & $2.8(1.3-6.0)^{*}$ & $1.9(0.5-7.1)$ \\
\hline Other & $1.5(0.8-2.8)$ & $2.6(2.0-3.3)^{*}$ & $3.2(2.0-5.2)^{*}$ & $2.0(1.3-3.1)^{*}$ \\
\hline \multicolumn{5}{|l|}{ Lifestyle } \\
\hline Smoker & $0.9(0.8-1.0)$ & $1.0(1.0-1.1)$ & $1.2(1.1-1.3)^{*}$ & $1.3(1.1-1.5)^{*}$ \\
\hline Overweight & $0.9(0.9-1.0)$ & $1.0(1.0-1.1)$ & $1.1(1.0-1.2)$ & $1.1(0.9-1.3)$ \\
\hline $\begin{array}{l}\text { Low physical } \\
\text { activity }\end{array}$ & $2.1(1.9-2.3)^{*}$ & $1.5(1.4-1.7)^{*}$ & $1.4(1.2-1.6)^{*}$ & $1.9(1.6-2.3)^{*}$ \\
\hline \multicolumn{5}{|l|}{ Welfare system } \\
\hline Bismarckian & $1.1(0.6-2.2)$ & $1.8(0.9-3.4)$ & $2.2(0.9-4.9)$ & $1.8(0.8-4.3)$ \\
\hline Eastern & $4.7(3.0-7.6)^{*}$ & $3.9(2.5-6.3)^{*}$ & $3.6(2.0-6.6)^{*}$ & $2.7(1.5-5.1)^{*}$ \\
\hline Southern & Ref & Ref & Ref & Ref \\
\hline \multicolumn{5}{|l|}{ Random effects } \\
\hline$\sigma$ & 0.377 & 0.378 & 0.465 & 0.471 \\
\hline LR test $\left(\right.$ prob $\left.>\chi^{2}\right)$ & $<0.001$ & $<0.001$ & $<0.001$ & $<0.001$ \\
\hline
\end{tabular}

OR: odds ratio; $95 \%$ CI: confidence interval 95\%; model adjusted by sociodemographic, lifestyles and welfare system. Ref: reference category. *Results statistically significant. Logistic regression test is carried out to check if random effects are statistically significant. Low educational level: International Standard Classification of Education (ISCED) 1; intermediate educational level: ISCED 2-4; high educational level: ISCED 5-6; smoker: daily smoker; overweight: Body Mass Index $>25$; low physical activity: no fulfillment of WHO recommendations. Bismarckian regime: Austria and Belgium; Eastern regime: Bulgaria, Czech Republic, Hungary, Latvia, Poland, Romania, Slovakia and Slovenia; Southern regime: Cyprus, Greece, Malta and Spain

\section{Discussion}

When generations were considered, we observed some differences in the role of individual and national factors in self-rated health. Self-assessed health worsens as generations grow older, and in addition, age becomes more important as individuals grow older as it is shown by the exponential effect of age observed in traditionalists and baby boomers. Individual sociodemographic and lifestyle factors showed a varying effect depending on the generation, with a growing importance of employment status in men over time and a variable effect of lifestyles, among others. The importance of the welfare system when understanding citizens' self-rated health was greater among the oldest male generations, with no differential effect in women.

Since generation boundaries are complex in Europe, this study has some limitations. In Austria, for instance, the baby boom started in 1956, while its estimated starting date in Belgium was 1950 (DeSA 2013). In addition, generational markers could not be standardized across all the countries analysed; nonetheless, to make the results 
Table 4 Determinants of low self-rated health by female generations using multilevel analyses, 14 European countries, European Health Interview Survey 2006-2009

\begin{tabular}{|c|c|c|c|c|}
\hline & $\begin{array}{l}\text { Traditionalists } \\
\text { OR }(95 \% \mathrm{CI})\end{array}$ & $\begin{array}{l}\text { Baby Boomers } \\
\text { OR }(95 \% \text { CI })\end{array}$ & $\begin{array}{l}\text { Generation X } \\
\text { OR }(95 \% \mathrm{CI})\end{array}$ & $\begin{array}{l}\text { Generation Y } \\
\text { OR }(95 \% \text { CI) }\end{array}$ \\
\hline \multicolumn{5}{|l|}{ Fixed effects } \\
\hline \multicolumn{5}{|l|}{ Sociodemographic } \\
\hline Age & $1.6(1.4-1.8)^{*}$ & $1.4(1.3-1.5)^{*}$ & $1.2(1.0-1.4)$ & $1.0(0.9-1.1)$ \\
\hline $\mathrm{Age}^{2}$ & $1.0(1.0-1.0)^{*}$ & $1.0(1.0-1.0)^{*}$ & $1.0(1.0-1.0)$ & $1.0(1.0-1.0)$ \\
\hline Married & Ref & Ref & Ref & Ref \\
\hline Single & $0.8(0.7-0.9)^{*}$ & $1.0(0.9-1.2)$ & $1.2(1.0-1.3)^{*}$ & $1.2(1.0-1.4)$ \\
\hline Widowed & $1.0(0.9-1.1)$ & $1.1(1.0-1.2)$ & $1.3(0.9-1.8)$ & $2.4(0.7-7.7)$ \\
\hline Divorced & $1.0(0.9-1.2)$ & $1.1(1.0-1.2)$ & $1.2(1.1-1.4)^{*}$ & $2.7(1.7-4.2)^{*}$ \\
\hline Low education & $3.0(2.6-3.4)^{*}$ & $3.5(3.2-3.9)^{*}$ & $2.5(2.1-3.0)^{*}$ & $2.3(1.7-3.0)^{*}$ \\
\hline $\begin{array}{c}\text { Intermediate } \\
\text { education }\end{array}$ & $1.9(1.6-2.1)^{*}$ & $2.0(1.7-2.2)^{*}$ & $1.6(1.4-1.8)^{*}$ & $1.4(1.2-1.7)^{*}$ \\
\hline High education & Ref & Ref & Ref & Ref \\
\hline Worker & Ref & Ref & Ref & Ref \\
\hline Unemployed & $2.4(1.2-5.0)^{*}$ & $2.0(1.7-2.2)^{*}$ & $1.7(1.5-2.0)^{*}$ & $1.2(1.0-1.5)$ \\
\hline Student & $3.3(1.4-7.7)^{*}$ & $2.3(1.2-4.4)^{*}$ & $1.2(0.7-2.1)$ & $0.8(0.7-1.0)$ \\
\hline Pensioner & $2.2(1.7-2.7)^{*}$ & $3.0(2.8-3.3)^{*}$ & $17.4(13.0-23.2)^{*}$ & $33.3(19.8-56.2) *$ \\
\hline Homemaker & $1.9(1.5-2.4)^{*}$ & $1.4(1.3-1.6)^{*}$ & $1.4(1.2-1.6)^{*}$ & $1.2(1.0-1.6)$ \\
\hline Other & $1.9(1.3-2.8)^{*}$ & $1.9(1.5-2.4)^{*}$ & $1.2(0.8-1.8)$ & $0.9(0.5-1.5)$ \\
\hline \multicolumn{5}{|l|}{ Lifestyle } \\
\hline Smoker & $0.8(0.7-1.0)^{*}$ & $1.1(1.0-1.2)^{*}$ & $1.5(1.3-1.6)^{*}$ & $1.6(1.4-1.9)^{*}$ \\
\hline Overweight & $1.3(1.2-1.4)^{*}$ & $1.4(1.4-1.5)^{*}$ & $1.4(1.3-1.6)^{*}$ & $1.4(1.2-1.7)^{*}$ \\
\hline $\begin{array}{l}\text { Low physical } \\
\text { activity }\end{array}$ & $1.6(1.5-1.8)^{*}$ & $1.2(1.2-1.3)^{*}$ & $1.2(1.1-1.3)^{*}$ & $1.2(1.1-1.4)^{*}$ \\
\hline \multicolumn{5}{|l|}{ Welfare system } \\
\hline Bismarckian & $0.7(0.4-1.4)$ & $1.1(0.5-2.2)$ & $1.6(0.8-3.0)$ & $2.2(1.1-4.5)^{*}$ \\
\hline Eastern & $3.9(2.5-6.0)^{*}$ & $2.9(1.7-4.8)^{*}$ & $2.4(1.5-3.9)^{*}$ & $2.5(1.5-4.2)^{*}$ \\
\hline Southern & Ref & Ref & Ref & Ref \\
\hline \multicolumn{5}{|l|}{ Random effects } \\
\hline$\sigma$ & 0.356 & 0.417 & 0.372 & 0.395 \\
\hline LR test $\left(\right.$ prob $\left.>\chi^{2}\right)$ & $<0.001$ & $<0.001$ & $<0.001$ & $<0.001$ \\
\hline
\end{tabular}

OR: odds ratio; $95 \%$ CI: confidence interval 95\%; model adjusted by sociodemographic, lifestyles and welfare system. Ref: reference category. *Results statistically significant. Logistic regression test is carried out to check if random effects are statistically significant. Low educational level: International Standard Classification of Education (ISCED) 1; intermediate educational level: ISCED 2-4; high educational level: ISCED 5-6; smoker: daily smoker; overweight: Body Mass Index $>25$; low physical activity: no fulfillment of WHO recommendations. Bismarckian regime: Austria and Belgium; Eastern regime: Bulgaria, regime: Czech Republic, Hungary, Latvia, Poland, Romania, Slovakia and Slovenia; Southern regime: Cyprus, Greece, Malta, and Spain comparable with other studies, a standard classification was chosen (Lancaster and Stillman 2002). We included in the analysis all the countries that participated in the EHIS wave 1 , even if these countries could not be representative of all the European population.

Alcohol consumption was not included in the analyses both, because it is closely linked to some countries' dietary habits and because the only information available was frequency of consumption, which limits comparability. As for the effects of tobacco, the lower impact among the oldest cohorts could be due to either the fact that many smokers have quitted or that heavy smokers might have died. In addition, we have used a restrictive definition of smoker (people who smoke daily), so the effect of smoking occasionally has not been evaluated. Income could not be considered because of the high number of missing values; to solve this limitation, education and employment were used as proxies of socioeconomic status. It is known that welfare provision differs between countries even when they are clustered into the same regime, which could hinder getting real conclusions (Bambra 2007). In addition, some limitations regarding the use of surveys should be 
acknowledged, such as using cross-sectional analyses or self-related information. Nonetheless, the possibility of using a large data set with comparable information of individuals from several European countries and different political contexts makes EHIS a good source of information. The use of multilevel regression models allows us to define and explore variations at different levels-micro and macro-after controlling for relevant explanatory variables. And last but not least, this is, to our knowledge, the first study that incorporates a generational perspective to the analysis of welfare systems and health, which gives us a wider insight and provides us with tools to develop specific public health policies.

Taking into account age and survey year, we know that at the time of the interview, traditionalists were over 63 years and baby boomers were between 44 and 63 . The role that age plays on self-rated health is different for men and women, and lifestyles and survival prevalence help us to understand these results. Male adults are more likely to engage in unhealthy habits that reduce their survival probabilities to senior stage; thus, male seniors are those who already surpass adulthood, because they have behaved healthier-or have changed their habits into healthier ones - than those who have already died (Ford et al. 2010). In addition, women have a higher life expectancy than men but with higher risks of disability (Chatterji et al. 2015).

Regarding sex differences when self-rating health, they could be found in all generations and were especially important in Southern countries. These results have been previously observed in countries like Spain (AguilarPalacio et al. 2015a; Malmusi et al. 2012) and could be explained by different factors, such as the family playing a fundamental role in Southern countries (Eikemo and Bambra 2008) or unpaid homemakers being mainly women. Even when women join the job market, they continue assuming the main role as homemakers (Bianchi 2011). On the contrary, Bismarckian countries have more intensive social and health-sensitive networks, which allow a better balance for vulnerable groups (Hurrelmann et al. 2011).

When we explored the influence of both the sociodemographic components and lifestyles on self-rated health, differences among generations were observed. People attitudes and values configure their behaviours, which justifies the consideration of a generational perspective on health studies. For example, people from Generation $\mathrm{Y}$ look different from previous generations, and they behave and think differently as well (Crumpacker and Crumpacker 2007). Regarding unemployment, its effect on health is more important for traditionalists. Despite being associated with low self-rated health even at early ages (AguilarPalacio et al. 2015b), unemployment in old ages reflects a high risk of vulnerability. Baby boomers who were studying were also a vulnerable group in terms of self-rated health, as well as young pensioners. The increase in life expectancy for baby boomers since the 1980s has not been matched by improved quality of life because of the concomitant increase in obesity and other associated chronic diseases (Swinburn et al. 2011). In addition, smoking habits in traditionalist women deserve a special mention. The social context for smokers has changed across time: from being linked to the wealthy to being concentrated amongst the economically marginalized groups (Lahelma et al. 2016). This fact-and also the selection bias derived from the surveillance of the healthiest individuals-could explain the effect observed in the oldest women.

In relation with welfare systems, Eastern countries presented the worst self-rated health levels. Although other studies have found better results for Bismarckian than for Southern countries (Eikemo et al. 2008), the countries included in the analysis may explain these differences. When welfare systems are included in the model, random effects decrease, whereas estimated parameters remain robust. This indicates the stability of the model and the explanatory power of the welfare regime. In addition, welfare systems played an important role on self-rated health in all generations, but its impact increased for traditionalists and baby boomers in men. The scope of social programmes in different age groups varies between countries-from youth-oriented in countries like Belgium to elderly-focused in Austria-but, in general terms, much more spending is devoted to the elderly (Lynch 2006). In addition, health is an accumulative process, so the access and quality of health goods and services can have a stronger effect in older generations, where the illness prevalence is higher and health problems become more serious. Regarding the differences by sex, further research should be conducted to evaluate whether women generations are taking advantage of these conditions or if they are being excluded of social policies.

As in the previous studies that relate self-rated health to generational cohorts (Badley et al. 2015; Carter and Kelly 2013), our results highlight the need to consider generational differences when developing health-promoting programmes. Depending on the target population, some policies will be more effective than others. As for individual determinants, employment protection is especially important for generations close to retirement, while policies to prevent disability are especially useful for young generations. Tobacco consumption plays an important role in Generation Y self-perception of health, which supports efforts to prevent young people from smoking. On the contrary, there are some programmes focused on individual determinants of health that would increase self-rated health across all generations. This would be the case of policies focused on improving people's educational level or 
promoting physical activity. In relation with the welfare system, its effect on self-rated health is higher in older generations and in men; this shows the protective effect of social services as vulnerability increases. This effectstronger in vulnerable groups-together with the weakening of welfare services in the current European context could increase health inequalities. Therefore, it is necessary to recover the role of welfare systems as health promoters, and to guarantee the access to services for all the population groups. Finally, it is important to highlight that there are also gender differences in each generation. Policies should be gender-sensitive, especially for some generations in which the gender distribution is not homogeneous, like traditionalists in Southern countries, where the rate of feminization is higher.

\section{Conclusions}

This study demonstrates that both individual factors and welfare systems affect self-rated health. The influence of these factors is not homogeneous across population, and it varies among generations. Therefore, this generational effect must be taken into account when developing proper policies to improve self-rated health for the European population. Current changes in welfare systems, the homogenizing effect of globalization, and the growing speed in generational changes should be considered in future research.

\section{Compliance with ethical standards}

Conflict of interest None.

\section{References}

Aguilar-Palacio I, Carrera-Lasfuentes P, Rabanaque MJ (2015a) Selfrated health and educational level in Spain: trends by autonomous communities and gender (2001-2012). Gac Sanit 29(1):37-43. https://doi.org/10.1016/j.gaceta.2014.07.004

Aguilar-Palacio I, Carrera-Lasfuentes P, Rabanaque MJ (2015b) Youth unemployment and economic recession in Spain: influence on health and lifestyles in young people (16-24 years old). Int J Public Health 60(4):427-435. https://doi.org/10.1007/ s00038-015-0668-9

Ahmad F, Jhajj AK, Stewart DE, Burghardt M, Bierman AS (2014) Single item measures of self-rated mental health: a scoping review. BMC Health Serv Res 14:398. https://doi.org/10.1186/ 1472-6963-14-398

Baćak V, Ólafsdóttir S (2017) Gender and validity of self-rated health in nineteen European countries. Scand $\mathrm{J}$ Public Health 45(6):647-653

Badley EM, Canizares M, Perruccio AV, Hogg-Johnson S, Gignac MA (2015) Benefits gained, benefits lost: comparing baby boomers to other generations in a longitudinal cohort study of self-rated health. Milbank Q 93(1):40-72

Bambra C (2007) Going beyond The three worlds of welfare capitalism: regime theory and public health research. J Epidemiol Community Health 61(12):1098-1102. https://doi.org/10.1136/ jech.2007.064295

Bambra C (2011) Health inequalities and welfare state regimes: theoretical insights on a public health 'puzzle'. J Epidemiol Community Health 65(9):740-745. https://doi.org/10.1136/jech. 2011.136333

Bianchi SM (2011) Family change and time allocation in American families. Ann Am Acad Polit Soc Sci 638(1):21-44

Bristow J (2016) The sociology of generations: new directions and challenges. Palgrave Macmillan, London

Carter MR, Kelly RK (2013) Self-reported health status, body mass index, and healthy lifestyle behaviors: differences between Baby Boomer and Generation X employees at a southeastern university. Workplace Health Saf 61(9):409-418. https://doi.org/10. 3928/21650799-20130827-67 (quiz 419)

Chatterji S, Byles J, Cutler D, Seeman T, Verdes E (2015) Health, functioning, and disability in older adults-present status and future implications. Lancet 385(9967):563-575. https://doi.org/ 10.1016/S0140-6736(14)61462-8

Chen H, Cohen P, Kasen S (2007) Cohort differences in self-rated health: evidence from a three-decade, community-based, longitudinal study of women. Am J Epidemiol 166(4):439-446

Cogin J (2012) Are generational differences in work values fact or fiction? Multi-country evidence and implications. Int J Hum Resour Manag 23(11):2268-2294

Crumpacker M, Crumpacker JM (2007) Succession planning and generational stereotypes: should HR consider age-based values and attitudes a relevant factor or a passing fad? Public Pers Manag 36(4):349-369

Department of Economic and Social Affairs (2013) World population prospects: the 2012 revision. Population Division of the Department of Economic and Social Affairs of the United Nations Secretariat, New York

Eikemo TA, Bambra C (2008) The welfare state: a glossary for public health. J Epidemiol Community Health 62(1):3-6. https://doi. org/10.1136/jech.2007.066787

Eikemo TA, Bambra C, Judge K, Ringdal K (2008) Welfare state regimes and differences in self-perceived health in Europe: a multilevel analysis. Soc Sci Med 66(11):2281-2295. https://doi. org/10.1016/j.socscimed.2008.01.022

Eurostat (2016) European Health Interview Survey (EHIS). http://ec. europa.eu/eurostat/web/microdata/european-health-interviewsurvey

Ferrera M (1996) The 'Southern model' of welfare in social Europe. J Eur Soc Policy 6(1):17-37

Ford ES, Li C, Zhao G, Pearson WS, Tsai J, Greenlund KJ (2010) Trends in low-risk lifestyle factors among adults in the United States: findings from the Behavioral Risk Factor Surveillance System 1996-2007. Prev Med 51(5):403-407. https://doi.org/10. 1016/j.ypmed.2010.08.002

Gesell I (2010) How to lead when the generation gap becomes your everyday reality. J Qual Particip 32(4):21

Hurrelmann K, Rathmann K, Richter M (2011) Health inequalities and welfare state regimes. A research note. J Public Health 19(1):3-13

Jylha M (2009) What is self-rated health and why does it predict mortality? Towards a unified conceptual model. Soc Sci Med 69(3):307-316. https://doi.org/10.1016/j.socscimed.2009.05.013

Lahelma E, Pietiläinen O, Ferrie J, Kivimäki M, Lahti J, Marmot M, Rahkonen O, Sekine M, Shipley M, Tatsuse T (2016) Changes over time in absolute and relative socioeconomic differences in 
smoking: a comparison of cohort studies from Britain, Finland, and Japan. Nicotine Tob Res 18(8):1697-1704

Lancaster LC, Stillman D (2002) When generations collide: Who they are. Why they clash. How to solve the generational puzzle at work. HarperCollins Publishers, New York City

Levickaite R (2010) Generations X, Y, Z: how social networks form the concept of the world without borders (the case of Lithuania). LIMES Cult Reg 3(2):170-183

Lynch J (2006) Age in the welfare state: the origins of social spending on pensioners, workers, and children. Cambridge University Press, Cambridge

Malmusi D, Artazcoz L, Benach J, Borrell C (2012) Perception or real illness? How chronic conditions contribute to gender inequalities in self-rated health. Eur J Pub Health 22(6):781-786. https://doi. org/10.1093/eurpub/ckr184
Meyer OL, Castro-Schilo L, Aguilar-Gaxiola S (2014) Determinants of mental health and self-rated health: a model of socioeconomic status, neighborhood safety, and physical activity. Am J Public Health 104(9): 1734-1741

Swinburn BA, Sacks G, Hall KD, McPherson K, Finegood DT, Moodie ML, Gortmaker SL (2011) The global obesity pandemic: shaped by global drivers and local environments. Lancet 378(9793):804-814. https://doi.org/10.1016/S0140-6736(11) 60813-1

World Health Organization (2010) Global recommendations on physical activity for health. WHO, Geneva

Wu S, Wang R, Zhao Y, Ma X, Wu M, Yan X, He J (2013) The relationship between self-rated health and objective health status: a population-based study. BMC Public Health 13(1):320 